\title{
HPV Vaccination Recommendation Practices among Adolescent Health Care Providers in 5 Countries
}

Hillary M. Topazian MSc ${ }^{1}$, Debanjali Kundu BSPH ${ }^{1}$, Kathryn Peebles MPH ${ }^{2}$, Silvina Ramos MSc ${ }^{3}$, Karen Morgan PhD, MA ${ }^{4,5}$, Chan Joo Kim MD ${ }^{6}$, Karin L. Richter MBChB, FC, MMed ${ }^{7}$, Noel T. Brewer $\mathrm{PhD}^{2}$, Mercè Peris MD, $\mathrm{MPH}^{8}$, Jennifer S. Smith PhD, $\mathrm{MPH}^{1,9, *}$

${ }^{1}$ Department of Epidemiology, Gillings School of Global Public Health, University of North Carolina, Chapel Hill, North Carolina

${ }^{2}$ Department of Health Behavior, Gillings School of Global Public Health, University of North Carolina, Chapel Hill, North Carolina

${ }^{3}$ Centro de Estudios de Estado y Sociedad, Buenos Aires, Argentina

${ }^{4}$ Perdana University, Royal College of Surgeons in Ireland School of Medicine, Kuala Lumpur, Malaysia

${ }^{5}$ Department of Psychology, Royal College of Surgeons in Ireland, Dublin, Ireland

${ }^{6}$ Department of Obstetrics and Gynecology, The Catholic University of Korea College of Medicine, St. Paul's Hospital, Seoul, Korea

${ }^{7}$ Department of Medical Virology, University of Pretoria, National Health Laboratory Service, Pretoria, South Africa

${ }^{8}$ Cancer Epidemiology Research Programme, Institut Catal?ad'Oncologia, Barcelona, Spain

${ }^{9}$ Lineberger Comprehensive Cancer Center, University of North Carolina, Chapel Hill, North Carolina 


\section{Abstract}

\section{Study Objective}

To assess adolescent health care providers' recommendations for, and attitudes towards human papillomavirus (HPV) vaccination in 5 countries.

Design

In-depth interviews of adolescent health care providers, 2013-2014.

\section{Setting}

Five countries where HPV vaccination is at various stages of implementation into national programs: Argentina, Malaysia, South Africa, South Korea, and Spain.

\section{Participants}

Adolescent health care providers $(\mathrm{N}=151)$ who had administered or overseen provision of adolescent vaccinations.

\section{Main Outcome Measures}

Frequency of HPV vaccination recommendation, reasons providers do not always recommend the vaccine, and facilitators to doing so, comfort level with recommending the vaccine, reasons for any discomfort, and positive and negative aspects of HPV vaccination.

\section{Results}

Over half of providers 82/151 (54\%) recommend HPV vaccination always or most of the time (range: $20 \%$ in Malaysia to $90 \%$ in Argentina). Most providers $112 / 151$ (74\%) said they were comfortable recommending HPV vaccination, although South Korea was an outlier 10/30 (33\%). Providers cited protection against cervical cancer $124 / 151$ (83\%) and genital warts 56/151 (37\%) as benefits of HPV vaccination. When asked about the problems with HPV vaccination, providers mentioned high cost $75 / 151$ (50\% overall; range: $26 \%$ in South Africa to $77 \%$ in South Korea) and vaccination safety $28 / 151$ (19\%; range: $7 \%$ in South Africa to 33\% in Spain). Free, low-cost, or publicly available vaccination 59/151 (39\%), and additional data on vaccination safety 52/151 (34\%) and efficacy 43/151 (28\%) were the most commonly cited facilitators of health provider vaccination recommendation.

\section{Conclusion}

Interventions to increase HPV vaccination should consider a country's specific provider concerns, such as reducing cost and providing information on vaccination safety and efficacy.

Key Words: Human papilloma virus; HPV-associated cancers; Cervical cancer; Vaccination; Health care provider recommendation 


\section{Introduction}

Cervical cancer is the fourth most common cancer in women worldwide, with an estimated 528,000 new cases and 266,000 deaths in $2012 .{ }^{1}$ Approximately $85 \%$ of cervical cancer cases occur in less developed regions, with high incidence in sub-Saharan Africa, South Asia, and Latin America. ${ }^{1}$ Almost all cases of cervical cancer (99\%) are attributable to human papillomavirus (HPV), a sexually transmitted infection affecting over 290 million women worldwide. ${ }^{2,3}$

With widespread use, prophylactic vaccination has the potential to markedly reduce the number of HPV infections, having been shown to decrease quadrivalent vaccine-associated type HPV prevalence by $77 \%$ among 18 - to 24 -year-olds in Australia, ${ }^{4}$ and by $56 \%$ among 14 - to 19 -year-olds in the United States despite only $32 \%$ coverage. ${ }^{5} \mathrm{HPV}$ vaccination also has potential to reduce the number of cervical cancer cases, as well as anal, vaginal, vulvar, penile, and oropharynx cancers, of which $31 \%-88 \%$ of incident cases worldwide are attributable to HPV. ${ }^{6}$ The first HPV vaccine was licensed in 2006. ${ }^{7}$ Today, 3 HPV vaccines are available globally, depending on country: a bivalent vaccine targeting antigens for HPV types 16 and 18; a quadrivalent vaccine (adding HPV types 6 and $11)^{2}$; and a nonavalent vaccine (further adding HPV types $31,33,45,52$, and 58 ) to provide protection against HPV types that cause approximately $90 \%$ of cervical cancers, as well as notable protection against vaginal, vulvar, and anal cancers. ${ }^{8}$ The World Health Organization's recommended target population for HPV vaccination is girls between the ages of 9 and 14 years, before sexual activity has started, with girls ages 15 and older and boys as secondary target populations. ${ }^{9}$ Many countries recommend HPV vaccination for boys and girls.

Differences in national availability of HPV vaccination has led to varying coverage rates worldwide. An estimated one-third of girls ages 10-20 years old in high-income countries had completed fullcourse HPV vaccination by 2014 , in contrast to only $7.2 \%, 0.1 \%$, and $1.0 \%$ in upper-middle income, lower-middle income, and low-income countries, respectively..$^{10}$ However, some countries have achieved enormous success in attaining high coverage rates, such as Rwanda, which has an estimated $97 \%$ full-course coverage for girls born in $2000,{ }^{11}$ and Malaysia, which reported $94 \%$ fullcourse coverage for 13-year-old girls in 2013. ${ }^{12}$

Physician recommendation is one of the most important influences on the decision to become vaccinated. ${ }^{13,14,15,16,17}$ Physicians can address vaccine-associated fears and hesitancy, and strongly endorse HPV vaccination. Yet quantitative global data on provider vaccination practices are relatively scarce ${ }^{18}$ Studies on providers' HPV vaccination recommendation practices in individual countries exist, ${ }^{14,19}$ including studies among health providers in Europe, which identify concerns about the vaccine's efficacy and long-term effects, provider's lack of time, and difficulty providing information to the target population of girls. ${ }^{20,}{ }^{21}$ However, none have described health provider responses across countries.

In this study, we present quantitative data from provider interviews in 5 countries (Argentina, Malaysia, South Africa, South Korea, and Spain) to assess adolescent health care providers' recommendations of and attitudes toward HPV vaccination.

\section{Materials and Methods}

\section{Study Participants}

Structured interviews were conducted face-to-face or via phone with adolescent vaccination providers between October 2013 and April 2014 using a standardized questionnaire, as previously reported. ${ }^{22}$ Providers from Argentina, Malaysia, South Africa, South Korea, and Spain were identified 
via convenience sampling and recruited through mail, e-mail, phone, or in-person conversations. Specific methods included outreach to study staff contacts, review of databases from national professional organizations, national health insurance reviews, and assessments, Web sites, and lists from external consultants.

Providers were considered eligible if they had ever administered or overseen provision of adolescent vaccinations, and if they were authorized to administer adolescent vaccinations according to each country's medical regulations. Because the overall purpose of the study was to assess the acceptability of 2-vs 3-dose vaccination schedules through an in-depth interview process, we aimed to recruit 30 health providers per country, consistent with previous studies of health providers' HPV vaccination perceptions. ${ }^{23,24}$

\section{Measures}

Provider demographic characteristics and information on attitudes toward HPV vaccination were collected by a study interviewer trained in structured interviewing techniques. Interview questionnaires were adapted from previously used surveys ${ }^{25,26,27}$ and newly developed items on the basis of HPV vaccination-related issues documented in the literature. Survey questions focused on the World Health Organization's HPV vaccination target group, girls ages 9-14 years, ${ }^{9}$ substituting the lower age range bound with each country's specific guideline (Argentina: 11 years of age; Malaysia: 13; South Africa: 9; South Korea: 11; and Spain: 11). Study eligibility, consent, and survey documents were translated from English into local languages when necessary. Specific survey questions related to provider HPV vaccination recommendations are included in Appendix A.

\section{Data Analyses}

In-country study staff double-entered deidentified data into English language EpiData (EpiData Association) forms, and translated data into English when necessary. Data were cleaned and analyzed at the University of North Carolina (UNC). Frequency tabulations were conducted on: (1) provider sociodemographic characteristics; (2) the frequency at which providers recommended routine HPV vaccination; (3) provider opinions about the advantages and disadvantages of HPV vaccination; (4) reasons for not always recommending HPV vaccination; (5) provider levels of comfort and reasons for any discomfort in recommending HPV vaccination; and (6) factors facilitating HPV vaccination recommendation. Odds ratios were estimated to determine associations between provider characteristics and provider frequency of HPV recommendation, comparing recommendation always or most of the time, relative to sometimes, hardly ever, or never. We used SAS version 9.4 (SAS Institute Inc) for all analyses.

\section{Ethical Considerations}

This study was approved by the UNC Office of Human Ethics and institutional review boards in each of the 5 collaborating countries. UNC study staff received institutional review board approval for analysis of deidentified secondary data. 


\begin{tabular}{|c|c|c|c|c|c|c|}
\hline Frequency of recommendation $(\mathrm{n}=151)$ & $\begin{array}{l}\text { Argentina } \\
(\mathrm{n}=30)\end{array}$ & $\begin{array}{c}\text { Malaysia } \\
\quad(n=30)\end{array}$ & $\begin{array}{l}\text { South } \\
\text { Africa } \\
(\mathrm{n}=31) \\
\end{array}$ & $\begin{array}{c}\text { South } \\
\text { Korea } \\
(\mathrm{n}=30)\end{array}$ & $\begin{array}{l}\text { Spain } \\
(\mathrm{n}=30)\end{array}$ & $\begin{array}{c}\text { Total } \\
(n=151)\end{array}$ \\
\hline Always & $73 \%$ & $13 \%$ & $42 \%$ & $17 \%$ & $77 \%$ & $44 \%$ \\
\hline Most of the time & $17 \%$ & $7 \%$ & $10 \%$ & $17 \%$ & $0 \%$ & $10 \%$ \\
\hline Sometimes / Hardly ever & $10 \%$ & $63 \%$ & $20 \%$ & $60 \%$ & $7 \%$ & $32 \%$ \\
\hline Never / I only vaccinate when a patient or her parent asks for it & $0 \%$ & $13 \%$ & $26 \%$ & $7 \%$ & $17 \%$ & $13 \%$ \\
\hline Not yet implemented & $0 \%$ & $0 \%$ & $3 \%$ & $0 \%$ & $0 \%$ & $1 \%$ \\
\hline Reasons providers do not always recommend $(n=83)^{a}$ & $\begin{array}{l}\text { Argentina } \\
(\mathrm{n}=8)\end{array}$ & $\begin{array}{c}\text { Malaysia } \\
(n=25)\end{array}$ & $\begin{array}{c}\text { South } \\
\text { Africa } \\
(\mathrm{n}=18)\end{array}$ & $\begin{array}{l}\text { South } \\
\text { Korea } \\
(\mathrm{n}=25)\end{array}$ & $\begin{array}{c}\text { Spain } \\
(\mathrm{n}=7)\end{array}$ & $\begin{array}{c}\text { Total } \\
(\mathrm{n}=83)\end{array}$ \\
\hline $\begin{array}{l}\text { Cost too high for patients / Hard to determine insurance coverage for HPV } \\
\text { vaccination }\end{array}$ & $38 \%$ & $36 \%$ & $6 \%$ & $48 \%$ & $14 \%$ & $31 \%$ \\
\hline Lack of time & $0 \%$ & $44 \%$ & $11 \%$ & $20 \%$ & $0 \%$ & $22 \%$ \\
\hline Not enough evidence for it / Lack of information / Not effective, safe, or useful & $25 \%$ & $4 \%$ & $11 \%$ & $12 \%$ & $57 \%$ & $14 \%$ \\
\hline $\begin{array}{l}\text { Not yet implemented and/or available or recently introduced / Refused / Don't } \\
\text { know }\end{array}$ & $0 \%$ & $4 \%$ & $56 \%$ & $0 \%$ & $14 \%$ & $14 \%$ \\
\hline $\begin{array}{l}\text { Up-front costs of ordering, stocking, and storing HPV vaccine is too high / } \\
\text { Inadequate or late reimbursement / Refrigerator space }\end{array}$ & $13 \%$ & $4 \%$ & $0 \%$ & $8 \%$ & $0 \%$ & $5 \%$ \\
\hline Too few patients want HPV vaccine / Hard to recommend HPV vaccination & $13 \%$ & $4 \%$ & $11 \%$ & $0 \%$ & $0 \%$ & $5 \%$ \\
\hline Difficult to discuss sexual issues & $0 \%$ & $4 \%$ & $0 \%$ & $4 \%$ & $0 \%$ & $2 \%$ \\
\hline Other $^{\mathrm{b}}$ & $13 \%$ & $0 \%$ & $6 \%$ & $8 \%$ & $14 \%$ & $6 \%$ \\
\hline \multicolumn{7}{|l|}{ Factors that would facilitate recommendation of HPV vaccination $(n=151){ }^{c}$} \\
\hline & $\begin{array}{l}\text { Argentina } \\
(\mathrm{n}=30)\end{array}$ & $\begin{array}{c}\text { Malaysia } \\
(n=30)\end{array}$ & $\begin{array}{l}\text { South } \\
\text { Africa } \\
(\mathrm{n}=31)\end{array}$ & $\begin{array}{l}\text { South } \\
\text { Korea } \\
(\mathrm{n}=30)\end{array}$ & $\begin{array}{l}\text { Spain } \\
(\mathrm{n}=30)\end{array}$ & $\begin{array}{c}\text { Total } \\
(n=151)\end{array}$ \\
\hline Free or low-cost vaccination / Vaccination publicly available & $33 \%$ & $50 \%$ & $26 \%$ & $57 \%$ & $30 \%$ & $39 \%$ \\
\hline More data on vaccine safety & $30 \%$ & $10 \%$ & $23 \%$ & $30 \%$ & $80 \%$ & $34 \%$ \\
\hline More data on long-term efficacy & $27 \%$ & $3 \%$ & $13 \%$ & $20 \%$ & $80 \%$ & $28 \%$ \\
\hline
\end{tabular}




\begin{tabular}{|c|c|c|c|c|c|c|}
\hline School-located program & $17 \%$ & $10 \%$ & $16 \%$ & $40 \%$ & $0 \%$ & $17 \%$ \\
\hline $\begin{array}{l}\text { Parents and/or family who are supportive of HPV vaccination / Greater } \\
\text { demand for vaccination / Meetings and campaigns targeting parents }\end{array}$ & $30 \%$ & $10 \%$ & $23 \%$ & $10 \%$ & $0 \%$ & $15 \%$ \\
\hline $\begin{array}{l}\text { More general information / Educational campaigns, promotions and } \\
\text { advertisements }\end{array}$ & $0 \%$ & $7 \%$ & $26 \%$ & $27 \%$ & $13 \%$ & $13 \%$ \\
\hline No need for booster doses / Fewer doses & $0 \%$ & $0 \%$ & $13 \%$ & $17 \%$ & $0 \%$ & $6 \%$ \\
\hline Other $^{\mathrm{d}}$ & $10 \%$ & $0 \%$ & $0 \%$ & $0 \%$ & $3 \%$ & $4 \%$ \\
\hline Nothing / Refused / Don't know & $10 \%$ & $23 \%$ & $3 \%$ & $0 \%$ & $0 \%$ & $7 \%$ \\
\hline
\end{tabular}

${ }^{\text {a }}$ Excluded providers who always recommend HPV vaccination

${ }^{b}$ Other responses $(n=5)$ : most are vaccinated $(n=1)$, no specific reason $(n=1)$, own concerns $(n=1)$, patient is too young $(n=1)$, no response $(n=1)$

${ }^{\mathrm{c}}$ Percentages may sum to more than 100 , given the possibility of multiple responses.

${ }^{d}$ Other responses $(n=4)$ : active surveillance $(n=1)$, doesn't recommend it $(n=1)$, information about follow-up $(n=1)$, more follow-up ( $\left.n=1\right)$ 


\section{Results}

Of 353 vaccine providers contacted, 151 enrolled in Argentina $(n=30)$, Malaysia $(n=30)$, South Africa ( $n$ $=31)$, South Korea $(n=30)$, and Spain $(n=30$; Table 1). Most providers in Argentina 30/30 $(100 \%)$, Spain 26/30 (87\%), and Malaysia 23/30 (77\%) had previously administered HPV vaccination to adolescents, with lower proportions in South Korea 15/30 (50\%) and South Africa 11/31 (35\%). A third 47/151 (31\%) were family, internal medicine, or general practitioners, 39/151 (26\%) were obstetrician-gynecologists, and 33/151 (22\%) were pediatricians. Most providers administered HPV vaccination in clinics 121/151 $(80 \%)$ and in private facilities only $81 / 151$ (54\%).

\section{Frequency of Routine HPV Vaccination Recommendation}

Many 67/151 (44\%) providers reported always recommending HPV vaccination, however, providers' recommendation frequency varied across countries (range: $13 \%$ in Malaysia to $77 \%$ in Spain; Table 1). Ten percent of providers 15/151 recommend vaccination most of the time (range: $0 \%$ in Spain to $17 \%$ in Argentina and South Korea) and a third 48/151 (32\%) of providers recommend HPV vaccination sometimes or hardly ever (range: $7 \%$ in Spain to 63\% in Malaysia; Fig. 1). A low percentage of providers 19/151 (13\%) would either never recommend HPV vaccination or only vaccinate when a patient or her parent requests it (range: $0 \%$ in Argentina to $26 \%$ in South Africa).

Overall, family medicine and general practitioners had lower odds of recommending HPV vaccination always or most of the time, relative to pediatricians (odds ratio [OR], 0.30; 95\% confidence interval [Cl], 0.11-0.80); provider type was otherwise not predictive of recommendation frequency (Table 2). Provision of adolescent vaccination at a school or hospital was not predictive of higher odds of a provider recommendation for HPV vaccination always or most of the time compared with provision at a clinic (school: OR, 1.13; 95\% Cl, 0.28-4.45; hospital: OR, 2.13; 95\% Cl, 0.94-4.79). Providers administering adolescent vaccination at a public practice had 3 times the odds of recommending HPV vaccination always or most of the time, relative to private practice providers (OR, 3.08; $95 \% \mathrm{Cl}, 1.38-6.88)$. Providers administering adolescent vaccination at public and private practices also had a higher odds of recommending HPV vaccination always or most of the time, relative to private practice providers, although estimates were imprecise (OR, 17.06; 95\% Cl, 3.75-77.63).

\section{Reasons for Not Always Recommending HPV Vaccination}

A third 26/83 (31\%) of providers who do not always recommend HPV vaccination considered cost to be too high for patients or that insurance coverage was difficult to determine (range: $6 \%$ in South Africa to $48 \%$ in South Korea; Table 1). 18/83 (22\%) providers said a lack of time was a reason for not always recommending vaccination (range: $0 \%$ in Argentina and Spain to 44\% in Malaysia). 12/83 (14\%) said that there was not enough evidence, a lack of information regarding HPV vaccination, or that it was not effective, safe, or particularly useful (range: $4 \%$ in Malaysia to $57 \%$ in Spain). Only 2/83 (2\%) of providers reported difficulty in discussing sexual issues as a reason for not always recommending HPV vaccination.

\section{Facilitators of HPV Vaccination Recommendation}

The most commonly cited facilitator of provider recommendation of HPV vaccination was free, low-cost, or publicly available vaccination 59/151 (39\%; range: $26 \%$ in South Africa to $57 \%$ in South Korea; Fig. 2). 


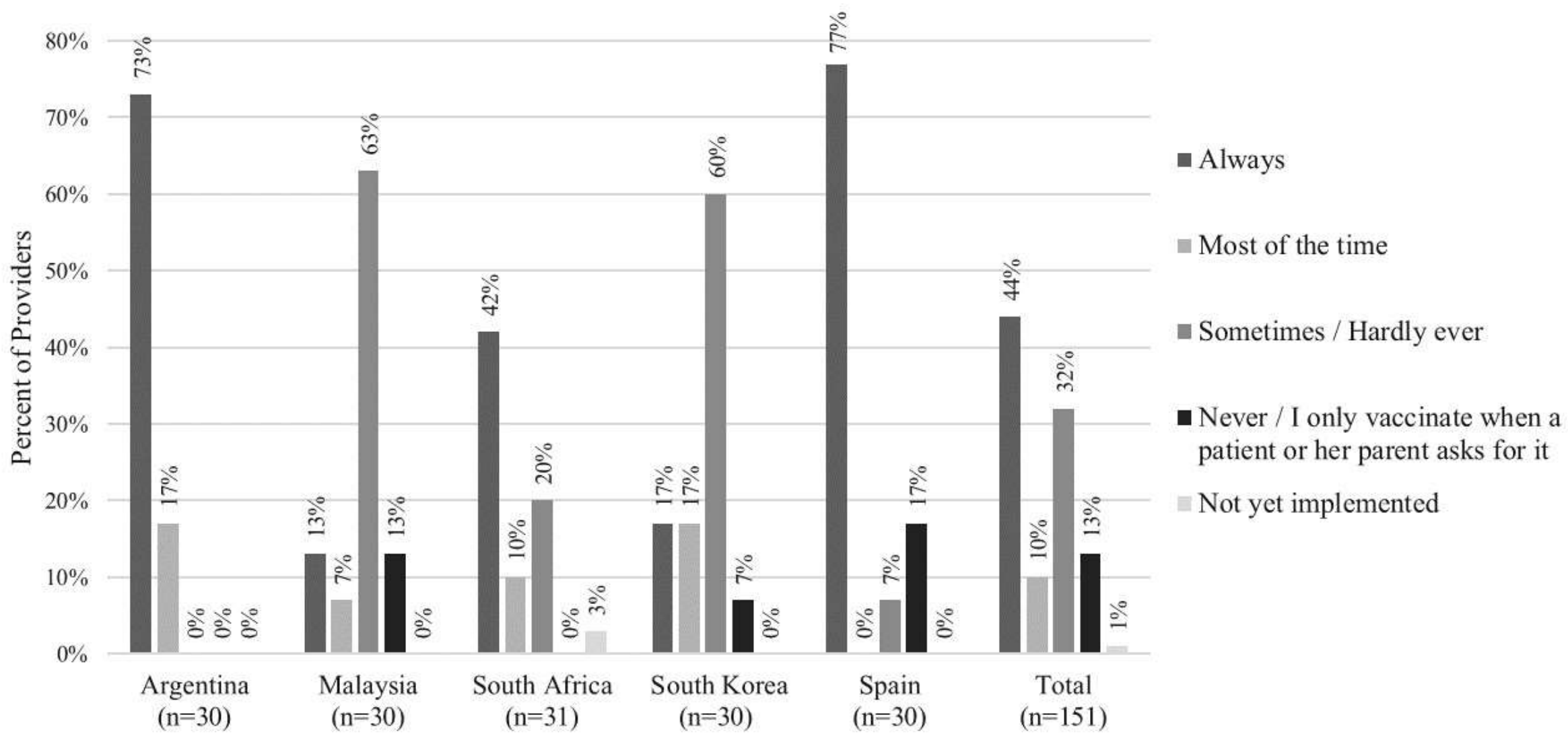

Fig. 1. Frequency of routine human papillomavirus vaccination recommendation by physicians in 5 countries $(N=151)$. 


\begin{tabular}{|c|c|c|c|}
\hline Characteristic & $\begin{array}{c}\text { Sample size } \\
(\mathrm{n}=141)^{\mathrm{a}}\end{array}$ & $\begin{array}{l}\text { Recommending always } \\
\text { or most of the time }(\%)\end{array}$ & Odds ratio $(95 \% \mathrm{CI})^{\mathrm{b}}$ \\
\hline \multicolumn{4}{|l|}{ Country } \\
\hline Argentina (reference) & 30 & 90.0 & 1.00 \\
\hline Malaysia & 27 & 22.2 & $0.03(0.01-0.14)$ \\
\hline South Africa & 28 & 57.1 & $0.15(0.04-0.61)$ \\
\hline South Korea & 29 & 34.5 & $0.06(0.01-0.24)$ \\
\hline Spain & 29 & 79.3 & $0.43(0.10-1.90)$ \\
\hline \multicolumn{4}{|l|}{ Provider type } \\
\hline Pediatrician (reference) & 33 & 66.7 & 1.00 \\
\hline Family medicine / general practice & 39 & 35.9 & $0.30(0.11-0.80)$ \\
\hline OB / GYN & 37 & 70.3 & $1.18(0.43-3.22)$ \\
\hline Nurse practitioner & 15 & 66.7 & $0.98(0.27-3.53)$ \\
\hline Pharmacist & 2 & 0.0 & $0.10(0.00-4.52)$ \\
\hline Midwife & 9 & 55.6 & $0.63(0.14-2.80)$ \\
\hline Internal medicine physician & 2 & 0.0 & $0.10(0.00-4.52)$ \\
\hline Other ${ }^{\mathrm{c}}$ & 7 & 71.4 & $1.12(0.20-6.49)$ \\
\hline \multicolumn{4}{|l|}{ Place of vaccine provision } \\
\hline Clinic (reference) & 115 & 55.7 & 1.00 \\
\hline School & 9 & 55.6 & $1.13(0.28-4.45)$ \\
\hline Hospital & 37 & 70.3 & $2.13(0.94-4.79)$ \\
\hline Health NGO and a pharmacy & 2 & 50.0 & $0.90(0.06-14.81)$ \\
\hline \multicolumn{4}{|l|}{ Type of clinic } \\
\hline Private (reference) & 25 & 92.0 & 1.00 \\
\hline Public & 40 & 67.5 & $3.08(1.38-6.88)$ \\
\hline Both & 77 & 40.3 & $17.06(3.75-77.63)$ \\
\hline \multicolumn{4}{|l|}{ Years of practice } \\
\hline 0-10 (reference) & 39 & 51.3 & 1.00 \\
\hline $11-20$ & 59 & 49.2 & $0.92(0.41-2.06)$ \\
\hline $21-30$ & 28 & 67.9 & $2.01(0.73-5.52)$ \\
\hline
\end{tabular}




\begin{tabular}{|l|c|c|c|}
\hline $31-50$ & 15 & 80.0 & $3.80(0.93-15.6)$ \\
\hline Average number of girls seen $^{\mathrm{d}}$ & & & 1.00 \\
\hline $0-10$ (reference) $^{-50}$ & 54 & 44.4 & $2.50(1.10-5.68)$ \\
\hline $51-400$ & 45 & 66.7 & $2.23(0.96-5.20)$ \\
\hline
\end{tabular}

${ }^{\text {a }}$ Excluding 10 observations because of missing data on frequency of provider recommendation

b All odds ratios are calculated for provider HPV vaccine recommendations "always / most of the time" relative to "sometimes / hardly ever / never"

${ }^{c}$ Other provider types include caregiver, health promotion practice, school-located nurse, and preventive medicine

${ }^{d} n=138$, excluding 3 additional observations because of missing data (2) and an outlier

$\mathrm{OB} / \mathrm{GYN}=$ obstetrician-gynecologist, $\mathrm{NGO}=$ non-governmental organization 


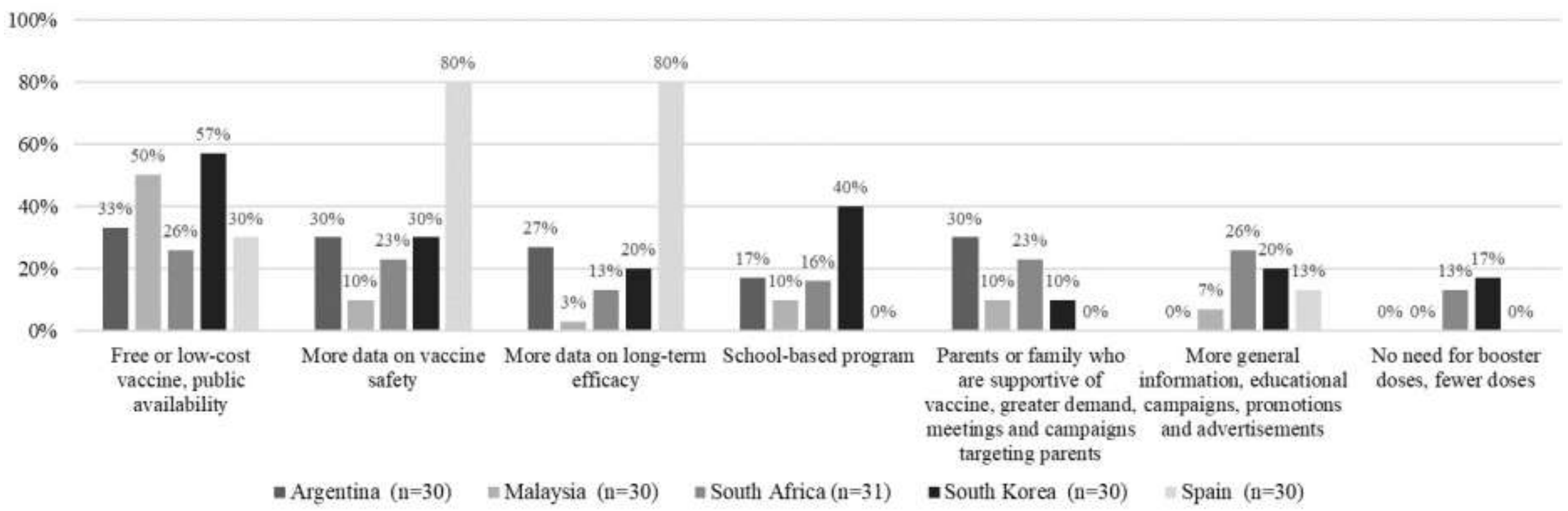

Fig. 2. Factors that would facilitate provider recommendation of human papillomavirus vaccination $(\mathrm{N}=151)$. Percentages might sum to more than 100 , because of the possibility of multiple responses. 


\begin{tabular}{|c|c|c|c|c|c|c|}
\hline & $\begin{array}{l}\text { Argentina } \\
(\mathrm{n}=30)\end{array}$ & $\begin{array}{c}\text { Malaysia } \\
(n=30)\end{array}$ & $\begin{array}{l}\text { South } \\
\text { Africa } \\
(\mathrm{n}=31)\end{array}$ & $\begin{array}{l}\text { South } \\
\text { Korea } \\
(\mathrm{n}=30)\end{array}$ & $\begin{array}{l}\text { Spain } \\
(\mathrm{n}=30)\end{array}$ & $\begin{array}{c}\text { Total } \\
(n=151)\end{array}$ \\
\hline \multicolumn{7}{|l|}{ Level of comfort in recommending vaccination } \\
\hline Very comfortable / A little comfortable & $83 \%$ & $83 \%$ & $84 \%$ & $33 \%$ & $87 \%$ & $74 \%$ \\
\hline $\begin{array}{l}\text { A little uncomfortable / Very } \\
\text { Uncomfortable }\end{array}$ & $17 \%$ & $13 \%$ & $10 \%$ & $67 \%$ & $13 \%$ & $24 \%$ \\
\hline Refused / Don't know & $0 \%$ & $0 \%$ & $6 \%$ & $0 \%$ & $0 \%$ & $1 \%$ \\
\hline $\begin{array}{l}\text { Reasons for discomfort in recommending } \\
\text { vaccination }^{\text {a }}\end{array}$ & $\underset{(\mathrm{n}=5)}{\text { Argentina }}$ & $\begin{array}{l}\text { Malaysia } \\
\quad(\mathrm{n}=4)\end{array}$ & $\begin{array}{l}\text { South } \\
\text { Africa } \\
(\mathrm{n}=3)\end{array}$ & $\begin{array}{l}\text { South } \\
\text { Korea } \\
(\mathrm{n}=20)\end{array}$ & $\begin{array}{c}\text { Spain } \\
(\mathrm{n}=4)\end{array}$ & $\begin{array}{l}\text { Total } \\
(\mathrm{n}=36)\end{array}$ \\
\hline Costs are too high & $40 \%$ & $25 \%$ & $0 \%$ & $80 \%$ & $25 \%$ & $56 \%$ \\
\hline Concerns about vaccine safety and/or side effects & $60 \%$ & $0 \%$ & $33 \%$ & $20 \%$ & $75 \%$ & $31 \%$ \\
\hline Uncomfortable discussing sexual health and/or sexually transmitted infections & $0 \%$ & $50 \%$ & $0 \%$ & $35 \%$ & $0 \%$ & $25 \%$ \\
\hline Unproven efficacy and/or not enough long-term data & $80 \%$ & $0 \%$ & $33 \%$ & $5 \%$ & $75 \%$ & $25 \%$ \\
\hline $\begin{array}{l}\text { Vaccine not publicly available / General uncertainty / Concerns about vaccine } \\
\text { messaging }\end{array}$ & $60 \%$ & $25 \%$ & $67 \%$ & $0 \%$ & $0 \%$ & $17 \%$ \\
\hline Don’t know / Other & $20 \%$ & $50 \%$ & $0 \%$ & $20 \%$ & $25 \%$ & $22 \%$ \\
\hline Providers opinions about advantages and disadvantages of HPV vaccination & $\begin{array}{l}\text { Argentina } \\
(\mathrm{n}=30)\end{array}$ & $\begin{array}{l}\text { Malaysia } \\
(\mathrm{n}=30)\end{array}$ & $\begin{array}{l}\text { South } \\
\text { Africa } \\
(\mathrm{n}=31)\end{array}$ & $\begin{array}{l}\text { South } \\
\text { Korea } \\
(\mathrm{n}=30)\end{array}$ & $\begin{array}{l}\text { Spain } \\
(\mathrm{n}=30)\end{array}$ & $\begin{array}{c}\text { Total } \\
(n=151)\end{array}$ \\
\hline \multicolumn{7}{|l|}{ Advantages of HPV vaccination ${ }^{\mathrm{a}}$} \\
\hline Protects against cervical cancer & $77 \%$ & $87 \%$ & $68 \%$ & $97 \%$ & $87 \%$ & $83 \%$ \\
\hline Protects against genital warts & $23 \%$ & $53 \%$ & $16 \%$ & $10 \%$ & $83 \%$ & $37 \%$ \\
\hline Long-lasting immunity / Prevents other HPV-related outcomes & $17 \%$ & $13 \%$ & $20 \%$ & $20 \%$ & $7 \%$ & $15 \%$ \\
\hline Vaccine is safe / Few adverse events & $13 \%$ & $0 \%$ & $13 \%$ & $13 \%$ & $3 \%$ & $9 \%$ \\
\hline $\begin{array}{l}\text { Vaccination could reduce the need for routine cervical cancer screening / } \\
\text { Vaccination gives providers opportunity to discuss sexual health issues with } \\
\text { patients }\end{array}$ & $13 \%$ & $7 \%$ & $19 \%$ & $0 \%$ & $3 \%$ & $9 \%$ \\
\hline
\end{tabular}




\begin{tabular}{|c|c|c|c|c|c|c|}
\hline Patients can receive other vaccinations at the same visit & $0 \%$ & $0 \%$ & $3 \%$ & $0 \%$ & $0 \%$ & $1 \%$ \\
\hline $\begin{array}{l}\text { I have never heard of the HPV vaccine / Nothing / I don't like anything about } \\
\text { the HPV vaccine }\end{array}$ & $7 \%$ & $0 \%$ & $7 \%$ & $0 \%$ & $13 \%$ & $5 \%$ \\
\hline \multicolumn{7}{|l|}{ Disadvantages of HPV vaccination $^{\mathrm{a}}$} \\
\hline Cost & $47 \%$ & $47 \%$ & $26 \%$ & $77 \%$ & $53 \%$ & $50 \%$ \\
\hline Unsafe / Causes adverse events & $13 \%$ & $16 \%$ & $7 \%$ & $23 \%$ & $33 \%$ & $19 \%$ \\
\hline Vaccination does not protect against all HPV types / not all cervical cancer & $23 \%$ & $0 \%$ & $16 \%$ & $17 \%$ & $33 \%$ & $18 \%$ \\
\hline Shot is painful & $20 \%$ & $20 \%$ & $10 \%$ & $17 \%$ & $13 \%$ & $16 \%$ \\
\hline 3 doses / Too many doses / Implementation problems & $17 \%$ & $7 \%$ & $20 \%$ & $13 \%$ & $7 \%$ & $13 \%$ \\
\hline $\begin{array}{l}\text { Vaccination would not reduce need for routine cervical cancer screening / } \\
\text { Requires providers to discuss sexual health issues with girls and/or parents }\end{array}$ & $20 \%$ & $0 \%$ & $3 \%$ & $0 \%$ & $20 \%$ & $9 \%$ \\
\hline $\begin{array}{l}\text { Negative perceptions / Lack of parental support / Need better awareness and/or } \\
\text { education campaigns }\end{array}$ & $13 \%$ & $3 \%$ & $10 \%$ & $7 \%$ & $7 \%$ & $8 \%$ \\
\hline Not enough evidence & $27 \%$ & $0 \%$ & $0 \%$ & $7 \%$ & $0 \%$ & $7 \%$ \\
\hline Vaccination does not lead to long-lasting immunity & $7 \%$ & $0 \%$ & $0 \%$ & $7 \%$ & $17 \%$ & $6 \%$ \\
\hline Not approved for all ages & $10 \%$ & $0 \%$ & $3 \%$ & $0 \%$ & $0 \%$ & $3 \%$ \\
\hline Likelihood of girls having sex would increase if vaccinated & $0 \%$ & $0 \%$ & $10 \%$ & $0 \%$ & $0 \%$ & $2 \%$ \\
\hline $\begin{array}{l}\text { Don't know / I have never heard of the HPV vaccine / Nothing / I like } \\
\text { everything about the HPV vaccine }\end{array}$ & $20 \%$ & $17 \%$ & $17 \%$ & $3 \%$ & $20 \%$ & $15 \%$ \\
\hline
\end{tabular}

${ }^{a}$ Percentages may sum to more than 100 , given the possibility of multiple responses. 
One-third of providers 52/151 (34\%) wanted more data on vaccination safety (range: $10 \%$ in Malaysia to $80 \%$ in Spain) and 43/151 (28\%) providers wanted more data on long-term vaccination efficacy (range: $3 \%$ in Malaysia to $80 \%$ in Spain). Seventeen percent $25 / 151$ said that a school-located program would be an effective facilitator (range: $0 \%$ in Spain to $40 \%$ in South Korea). 20/151 (13\%) providers desired more general information, or educational campaigns, promotions, and advertisements to facilitate recommendation of vaccination (range: $0 \%$ in Argentina to $26 \%$ in South Africa).

\section{Provider Opinions about HPV Vaccination}

Most providers 125/151 (83\%) listed protection against cervical cancer as one of the benefits of HPV vaccination (range: $68 \%$ in South Africa to $97 \%$ in South Korea; Table 3). In addition, 56/151 (37\%) providers listed protection against genital warts (range: 10\% in South Korea to 83\% in Spain). 23/151 (15\%) considered the vaccination's long-lasting immunity and prevention of other HPV-related outcomes as beneficial (range: $7 \%$ in Spain to 20\% in South Korea and South Africa). 13/151 (9\%) providers cited vaccination safety and lack of adverse events as a benefit of vaccination.

Cost was considered a major disadvantage for half of providers $75 / 151$ (50\%, range: $26 \%$ in South Africa to $77 \%$ in South Korea). $28 / 151$ (19\%) providers stated that HPV vaccination might be unsafe or cause adverse events (range: $7 \%$ in South Africa to 33\% in Spain). Providers also expressed concerns that the vaccination does not protect against all HPV types or cervical cancers $27 / 151$ (18\%; range: $0 \%$ in Malaysia to $33 \%$ in Spain), the pain of the shot 24/151 (16\%; range: $10 \%$ in South Africa to $20 \%$ in Argentina and Malaysia), and that there is not enough evidence for HPV vaccination 10/151 (7\%; range: $0 \%$ in Malaysia, South Africa, and Spain to $27 \%$ in Argentina). Only 3/151 providers (2\%), all of whom were from South Africa, stated that the likelihood of girls having sex would increase if vaccinated.

\section{Comfort in Recommending HPV Vaccination and Reasons for Any Discomfort}

Overall, most providers $112 / 151$ (74\%) reported being comfortable recommending vaccination, with South Korea being a low outlier $10 / 30$ (33\%; Table 3). Only a quarter of providers $36 / 151$ (24\%) were uncomfortable recommending vaccination. Of the 36 providers who were uncomfortable recommending vaccination, approximately half 20/36 (56\%) cited high costs as a reason for discomfort (range: $0 \%$ in South Africa to $80 \%$ in South Korea). A third of providers 11/36 (31\%) stated concerns about vaccination safety and side effects (range: $0 \%$ in Malaysia to $75 \%$ in Spain). Only $9 / 36$ providers (25\%), 7 in Korea and 2 in Malaysia, stated they were uncomfortable discussing sexual health or sexually transmitted infections.

\section{Discussion}

In our study of 151 adolescent vaccine providers we assessed frequency of routine provider recommendations for HPV vaccination in 5 countries. Protection against cervical cancer and genital warts were the most commonly cited benefits of HPV vaccination, whereas disadvantages were cost, safety, and efficacy concerns. Offering free, low-cost, or publicly available vaccination, and providing more data on safety and long-term efficacy were factors that could increase provider recommendations. 
Addressing specific provider concerns is of critical importance, because previous research has suggested that provider recommendation is the strongest predictor of adolescent HPV vaccination. ${ }^{13-17}$

Relatively high HPV vaccination recommendation frequencies and high levels of comfort in recommending vaccination were reported by providers from Argentina, Spain, and South Africa. Surveys of gynecologists and pediatricians in Argentina have also found high acceptability, with $82 \%$ and $75 \%$ prescribing HPV vaccination, respectively. ${ }^{28,29}$ Systematic reviews have consistently reported high acceptability of HPV vaccination in sub-Saharan Africa among adolescent girls, women, parents, and health care providers. ${ }^{30,31}$ Adolescent providers from South Korea and Malaysia in our study recommended vaccination at a relatively lower frequency than the overall group. Low recommendation frequencies in these Asian countries aligns with other research from South Korea, Thailand, Taiwan, and Malaysia, where only $56 \%$ of physicians had initiated conversations regarding HPV vaccination, and a third of these providers reported discomfort in doing so. ${ }^{13}$ In Malaysia and in the study region of Spain, vaccinations are systematically administered through school-located programs, yet in our study only $3 / 30(10 \%)$ providers in Spain and 1/30 (3\%) provider from Malaysia administered vaccines in schools. Results might have differed if interviews had been limited to school-located providers, particularly in Malaysia, where the rate of full-course HPV vaccination completion is high. ${ }^{12}$ Cost of HPV vaccination in Malaysia is substantial for girls not covered under school programs, which might also partially explain provider hesitancy (Dr Karen Morgan, written communication, November 2017). Because the study sample represents a larger catchment of adolescent health care providers, results could provide insight into efforts to increase vaccination uptake in other regions that use a clinic-based approach or in countries that supplement school-located programs with clinic-based HPV vaccination.

In our study, protection against cervical cancer and genital warts were the most frequently cited advantages of HPV vaccination, consistent with literature from Malaysia, where over $95 \%$ of providers agreed that HPV vaccines can prevent cervical cancer, ${ }^{14}$ and in India, where $81 \%$ of surveyed health care professionals were aware that vaccination prevents cervical cancer. ${ }^{19}$

Concern about cost was the most frequently cited disadvantage of HPV vaccination among providers within each country. Similarly, cost was the most important consideration in willingness to vaccinate among health care providers in Vietnam, which does not have a routine HPV immunization program. ${ }^{32}$ Over a third (59/151) of providers in our study cited free, low-cost, or publicly available vaccination, and more data on vaccination safety (52/151) as factors that would facilitate vaccination recommendation. South Korea has already moved to address cost by including HPV vaccination in the National Immunization Program since 2016 and offering 2 doses of either the bivalent and quadrivalent vaccine for free to girls and boys younger than the age of 12 years. ${ }^{33}$

Several countries have also achieved high coverage rates by offering the vaccination through schoolbased programs, simultaneously reducing cost and increasing accessibility for greater coverage of the target population. ${ }^{34}$ Providers in our study do not always recommend HPV vaccination because of a lack of time, particularly in Malaysia and South Korea. Likewise, in another study among 480 physicians across 4 countries in Asia, the most common impediments included the perceived time-consuming nature of a discussion about HPV vaccination with parents. ${ }^{13}$ Twenty-one percent of physicians from the same study thought that HPV vaccination is a sensitive subject that parents might object to discussing, and $16 \%$ found it difficult to know how and when to initiate the discussion. In contrast, very few providers in our study cited difficulty in discussing sexual issues with parents of girls as a reason why 
they do not always recommend HPV vaccination. Research in Malaysia has shown that among 247 HPV vaccination providers, members of certain ethnic groups were more likely to view cultural sensitivity as an issue in HPV vaccination recommendation, because HPV infection is sexually transmitted. ${ }^{14}$ The level of hesitation to discuss sexual issues with parents might vary depending on the culture in which a provider practices.

Regarding additional barriers, adolescent providers in our study said they do not always recommend vaccination because of a lack of evidence, insufficient information, or that the vaccination is not effective, safe, or useful. These cited disadvantages align with research in Europe among health care professionals, which reported fear of adverse side effects and vaccination safety, poor information, and perceived ineffectiveness were all reasons for provider hesitancy. ${ }^{35}$ Vaccination-related side effects occurring during receipt of HPV vaccination in European countries received national attention and programmatic change, leading to physician doubts about vaccination safety. ${ }^{36}$ Provider attitudes toward vaccination have wide-reaching influence on uptake; advice by a nurse or physician whether positive or negative, was a primary source of association with the vaccination status of girls in Spain. ${ }^{37}$

National HPV vaccination availability at the time of our survey might have influenced provider recommendation practices. In Argentina, Malaysia, and Spain, HPV vaccination became part of the National Immunization Program under Ministry of Health recommendations for adolescent females in 2011, 2010, and 2007, respectively, before the start of our study. ${ }^{29,38-41}$ Full-course HPV vaccination coverage rates were $50.0 \%$ in Argentina (birth cohort year 2000), $81.6 \%$ in the study region of Spain (birth cohort year 2001), and $94.3 \%$ (girls age 13 years in 2013) in Malaysia. ${ }^{10,12}$ In contrast, South Korea did not include HPV vaccination in their National Immunization Program until 2016.33 In South Africa, HPV vaccination was not yet included in the national program, and was only available in the private sector, with a school-based HPV vaccination program beginning in April $2014 .{ }^{42}$

Study results highlight specific provider concerns that can be targeted through programmatic efforts to increase the quantity and frequency of routine provider recommendations. Making education a priority for health care providers before HPV vaccination is widely available is recommended to increase understanding of the vaccination's benefits and limitations, and to encourage provider discussions with patients. ${ }^{43}$ In a study of 427 health care providers in the United States, the HPV knowledge score of providers increased after attending an educational lecture, ${ }^{44}$ and further research among American College of Obstetricians and Gynecologists fellows showed that physicians who responded accurately about protective benefits were more likely to administer the HPV vaccination. ${ }^{45}$ Among 480 Asian physicians surveyed, two-thirds said that a recommendation of HPV vaccination from the Ministry of Health or the government would facilitate their own recommendation that mothers vaccinate their daughters during the next year,13 iterating the role of policymakers in promoting physician recommendation.

The primary strength of our study is the aggregation of provider HPV vaccination recommendation data across 5 countries. Although previous studies have considered provider recommendations in individual countries or compared ethnic groups within the United States, ${ }^{46}$ to our knowledge, none to date have systematically described results from different countries. Including providers who frequently and rarely recommend HPV vaccination offers a wide range of perspectives on barriers and facilitators.

One study limitation stems from the relatively small sample sizes within each country; the group of providers surveyed might not be representative of all adolescent vaccination providers within each 
country. Conclusions comparing individual sites should be interpreted with caution because of differences in cultural context, timing of vaccination introduction, as well as other unmeasured factors. Another limitation is that our study did not capture information on the strength and quality of provider recommendations. Previous research has shown that behavior changes such as making presumptive statements that assume parental readiness to vaccinate, taking an active role in the vaccination decision, and giving a high-quality recommendation to parents increases HPV vaccination uptake. ${ }^{18,47,48}$ Survey questions focused on provider recommendations and provider attitudes toward HPV vaccination among adolescent girls specifically, although findings are also likely to apply to provider recommendations for adolescent boys. Although this study focused on HPV vaccination among adolescents given the vaccination results in optimal protection before exposure, ${ }^{49}$ vaccination of pregnant mothers might also result in antibodies to prevent vertical transmission of HPV. ${ }^{50}$

Our study reports globally relevant data on provider HPV vaccination recommendations. Because provider recommendation is one of the principal factors that motivate vaccination uptake, programs and research should focus on reducing barriers and enhancing the facilitators that providers identify to recommending HPV vaccination. Organizations are currently working to increase the frequency and quality of HPV vaccination recommendations, including the National HPV Vaccination Roundtable, 51 which has created HPV vaccination action guides for health systems, private practices, physicians, and other health care providers. The American Cancer Society has also created a guidebook for clinicians that uses evidence-based strategies to increase HPV vaccination. ${ }^{52}$ Other professional organizations such as the Asociación Española de Pediatría ${ }^{53}$ in Spain, or advisory components of Ministries of Health such as the Korea Advisory Committee on Immunization Practices ${ }^{54}$ could also be avenues for increasing HPV vaccination administration by providers. Findings from our study have implications for designing public health interventions that are targeted to a country's specific provider concerns, such as subsidizing cost, increasing the availability of information, and providing sufficient data on vaccination safety and efficacy.

\section{Acknowledgments}

The authors thank Margaret Wang for her assistance in the review of the manuscript.

This study was an ancillary study to the GlaxoSmithKline Biologicals SA-funded parent study (ID: 117339), which aimed to compare 2- vs 3-dose HPV vaccination. GSK was not involved in the conduct and analysis of this ancillary study. GSK was provided the opportunity to review the manuscript for accuracy, but the authors are solely responsible for final content and interpretation.

Hillary M. Topazian was supported by the UNC's Graduate School Doctoral Merit Assistantship for study in Epidemiology during the completion of this work. 


\section{References}

1. Ferlay J, Soerjomataram I, Ervik M, et al: GLOBOCAN 2012 v1.0, Cancer Incidence and Mortality Worldwide: IARC CancerBase No. 11. Lyon, France, International Agency for Research on Cancer, 2013

2. Preparing for the Introduction of HPV Vaccines: Policy and Programme Guidance for Countries. Geneva, World Health Organization, 2006

3. Puranen $\mathrm{M}$, Yliskoski M, Saarikoski S, et al: Vertical transmission of human papillomavirus from infected mothers to their newborn babies and persistence of the virus in childhood. Am J Obstet Gynecol 1996; 174:694

4. Tabrizi SN, Brotherton JM, Kaldor JM, et al: Fall in human papillomavirus prevalence following a national vaccination program. J Infect Dis 2012; 206: 1645

5. Markowitz LE, Hariri S, Lin C, et al: Reduction in human papillomavirus (HPV) prevalence among young women following HPV vaccine introduction in the United States, National Health and Nutrition Examination Surveys, 2003-2010. J Infect Dis 2013; 208:385

6. de Martel C, Plummer M, Vignat J, et al: Worldwide burden of cancer attributable to HPV by site, country and HPV type. Int J Cancer 2017; 141:664

7. Sharma R: HPV vaccine: a breakthrough in prevention of cervical cancer. Apollo Med 2012; 9:87

8. Printz C: FDA approves Gardasil 9 for more types of HPV. Cancer 2015; 121:1156

9. World Health Organization: Human papillomavirus vaccines: WHO position paper, May 2017. Wkly Epidemiol Rec 2017; 92:241

10. Bruni L, Diaz M, Barrionuevo-Rosas L, et al: Global estimates of human papillomavirus vaccination coverage by region and income level: a pooled analysis. Lancet Glob Health 2016; 4:e453 11. Bruni L, Barrionuevo-Rosas L, Albero G, et al: ICO/IARC Information Centre on HPV and Cancer (HPV Information Centre): Barcelona, Spain. Human Papillomavirus and Related Diseases in Rwanda. Summary Report 27 July 2017.

12. Ministry of Health Malaysia: Childhood Immunisation Coverage, 2013. Available from: http://www.moh.gov.my/english.php/pages/view/408. Accessed October 5, 2017.

13. Chow SN, Soon R, Park JS, et al: Knowledge, attitudes, and communication around human papillomavirus (HPV) vaccination amongst urban Asian mothers and physicians. Vaccine 2010; 28:3809

14. Wong LP: Physicians' experiences with HPV vaccine delivery: evidence from developing country with multiethnic populations. Vaccine 2009; 27: 1622

15. Brewer NT, Fazekas KI: Predictors of HPV vaccine acceptability: a theory-informed, systematic review. Prev Med (Baltimore) 2007; 45:107

16. Oh JK, Lim MK, Yun EH, et al: Awareness of and attitude towards human papillomavirus infection and vaccination for cervical cancer prevention among adult males and females in Korea: a nationwide interview survey. Vaccine 2010; 28:1854

17. Rosenthal SL, Weiss TW, Zimet GD, et al: Predictors of HPV vaccine uptake among women aged 19-26: importance of a physician's recommendation. Vaccine 2011; 29:890

18. Gilkey MB, Calo WA, Moss JL, et al: Provider communication and HPV vaccination: the impact of recommendation quality. Vaccine 2016; 34:1187

19. Chawla PC, Chawla A, Chaudhary S: Knowledge, attitude \& practice on human papillomavirus vaccination: a cross-sectional study among healthcare providers. Indian J Med Res 2016; 144:741 20. Gottvall M, Tydén T, Larsson M, et al: Challenges and opportunities of a new HPV immunization program: perceptions among Swedish school nurses. Vaccine 2011; 29:4576

21. Oscarsson MG, Dahlberg A, Tydén T: Midwives at youth clinics attitude to HPV vaccination and their role in cervical cancer prevention. Sex Reprod Healthc 2011; 2:137

22. Vielot NA, Goldberg SK, Zimet G, et al: Acceptability of multipurpose human papillomavirus vaccines among providers and mothers of adolescent girls: a mixed-methods study in five countries. Papillomavirus Res 2017; 3:126 
23. Perkins RB, Clark JA: What affects human papillomavirus vaccination rates? A qualitative analysis of providers' perceptions. Womens Health Issues 2012; 22:e379

24. Javanbakht $M$, Stahlman $S$, Walker $S$, et al: Provider perceptions of barriers and facilitators of HPV vaccination in a high-risk community. Vaccine 2012; 30:4511

25. Brewer NT, Gottlieb SL, Reiter PL, et al: Longitudinal predictors of human papillomavirus vaccine initiation among adolescent girls in a high-risk geographic area. Sex Transm Dis 2011; 38:197 26. Reiter PL, Brewer NT, Gottlieb SL, et al: Parents' health beliefs and HPV vaccination of their adolescent daughters. Soc Sci Med 2009; 69:475

27. McRee AL, Brewer NT, Reiter PL, et al: The Carolina HPV immunization attitudes and beliefs scale (CHIAS): scale development and associations with intentions to vaccinate. Sex Transm Dis 2010;

$37: 234$

28. PATH, HPV vaccines: evidence for impact: small grants program final report.

Available: http://www.rho.org/files/PATH_HPV_vaccines_small_grants_report_2013.pdf.

29. Arrossi S, Maceira V, Paolino M, et al: Acceptability and uptake of HPV vaccine in Argentina

before its inclusion in the immunization program: a population-based survey. Vaccine 2012; 30:2467

30. Cunningham MS, Davison C, Aronson KJ: HPV vaccine acceptability in Africa: a systematic review.

Prev Med (Baltimore) 2014; 69:274

31. Perlman S, Wamai RG, Bain PA, et al: Knowledge and awareness of HPV vaccine and acceptability to vaccinate in Sub-Saharan Africa: a systematic review. PLoS One 2014; 9 , e90912

32. Asiedu GB, Breitkopf CR, Kremers WK, et al: Vietnamese health care providers' preferences regarding recommendation of HPV vaccines. Asian Pac J Cancer Prev 2015; 16:4895

33. KCDC, National Immunization Program for Children. Available:

http://www.cdc.go.kr/CDC/eng/contents/CdcEngContentView.jsp?cid574258\&menulds5HOME002NU0576-MNU0586. Accessed August 28, 2017.

34. Walling EB, Benzoni N, Dornfeld J, et al: Interventions to improve HPV vaccine uptake: a systematic review. Pediatrics 2016; 138:e20153863

35.Yaqub O, Castle-Clarke S, Sevdalis N, et al: Attitudes to vaccination: a critical review. Soc Sci Med $2014 ; 112: 1$

36.Markowitz LE, Tsu V, Deeks SL, et al: Human papillomavirus vaccine introduction - the first five years. Vaccine 2012; 30:F139

37.Navarro-Illana P, Navarro-Illana E, Vila-Candel R, et al: Drivers for human papillomavirus vaccination in Valencia (Spain). Gac Sanit 2017. [Epub ahead of print].

38. Ministry of Health Malaysia: Cervical Cancer Vaccine. Gardasil ${ }^{\circledR}$ And Cervarix ${ }^{\circledast}$. Health Technology Assessment Section, Medical Development Division Ministry of Health Malaysia 2011, Report No. 008/2011.

39.Elbasha EH, Dasbach EJ, Insinga RP, et al: Model for assessing human papillomavirus vaccination strategies. Emerg Infect Dis 2007; 13:28

40. Argentina. Presidencia de la Nación, Boletín Oficial de la República Argentina. Resolution 563/2011. Year CXIX, Ner 32149. Available:

http://www.boletinoficial.gov.ar/DisplayPdf.aspx?s5BPBCF\&f520110513. Accessed August 29, 2017.

41. Bruni L, Barrionuevo-Rosas L, Albero G, et al: ICO/IARC Information Centre on HPV and Cancer (HPV Information Centre): Barcelona, Spain. Human Papillomavirus and Related Diseases in Spain. Summary Report 27 July.

42. Michelow P, Firnhaber C: HPV vaccination in Southern Africa: a jab of hope in the fight against cervical cancer. Cancer Cytopathol 2016; 124:695

43. Sherris J, Friedman A, Wittet $S$, et al: Chapter 25: education, training, and communication for HPV vaccines. Vaccine 2006; 24S3:S3/210

44. Berenson $A B$, Rahman $M$, Hirth JM, et al: A brief educational intervention increases providers' human papillomavirus vaccine knowledge. Hum Vaccin Immunother 2015; 11:1331

45. Leddy MA, Anderson BL, Gall S, et al: Obstetrician-gynecologists and the HPV vaccine: practice patterns, beliefs, and knowledge. J Pediatr Adolesc Gynecol 2009; 22:239 
46.Ylitalo KR, Lee $\mathrm{H}$, Mehta NK: Health care provider recommendation, human papillomavirus vaccination, and race/ethnicity in the US National Immunization Survey. Am J Public Health 2013; 103:164

47. Brewer NT, Hall ME, Malo TL, et al: Announcements versus conversations to improve HPV vaccination coverage: a randomized trial. Pediatrics 2017; 139: e20161764

48. Moss JL, Reiter PL, Rimer BK, et al: Collaborative patient-provider communication and uptake of adolescent vaccines. Soc Sci Med 2016; 159:100

49. Hildesheim A, Herrero R: Human papillomavirus vaccine should be given before sexual debut for maximum benefit. J Infect Dis 2007; 196:1431

50. Matys K, Mallary S, Bautista O, et al: Mother-infant transfer of anti-human papillomavirus (HPV) antibodies following vaccination with the quadrivalent HPV (type 6/11/16/18) virus-like particle vaccine. Clin Vaccine Immunol 2012; 19:881

51. National HPV Roundtable: The National HPV Roundtable. Available: http://hpvroundtable.org. Accessed April 3, 2018.

52. American Cancer Society: Mission: HPV Cancer Free: Steps for Increasing HPV Vaccination in Practice: An Action Guide to Implement Evidence-based Strategies for Clinicians. Atlanta, Georgia, American Cancer Society, Inc, 2016

53. AEP: Asociación Española de Pediatría. Available: http://www.aeped.es. Accessed June 4, 2018.

54. Cho HY, Kim CH, Go UY, et al: Immunization decision-making in the Republic of Korea: the structure and functioning of the Korea Advisory Committee on Immunization Practices. Vaccine 2010; 28:A91 


\section{Appendix A}

Table S1. Quantitative Questions That Assessed HPV Vaccination Recommendation Practices among Adolescent

\section{Health Care Providers}

\begin{tabular}{|c|c|c|}
\hline Construct & Question & Answer options \\
\hline Frequency of routine recommendation & $\begin{array}{l}\text { How often do you recommend HPV vaccination to parents } \\
\text { of girls in your practice (or school)? }\end{array}$ & $\begin{array}{l}\text { - Always } \\
\text { - Most of the time } \\
\text { - Sometimes } \\
\text { - Hardly ever } \\
\text { - Never } \\
\text { - I only vaccinate when a patient or her parent asks for it } \\
\text { - Not yet implemented } \\
\text { - Refused } \\
\text { - Don't know } \\
\text { - Other, open-ended response }\end{array}$ \\
\hline Reason provider does not recommend vaccine & $\begin{array}{l}\text { What is the main reason you do not always recommend the } \\
\text { HPV vaccine to parents of girls in your practice (or } \\
\text { school)? }\end{array}$ & $\begin{array}{l}\text { Select only one: } \\
\text { - Too few patients want HPV vaccine } \\
\text { - Hard to recommend HPV vaccine } \\
\text { - Cost too high for patients } \\
\text { - Initial costs of ordering, stocking and storing HPV vac- } \\
\text { cine too high } \\
\text { - Inadequate or late reimbursement } \\
\text { - Difficult to determine insurance coverage for HPV } \\
\text { vaccine } \\
\text { - Refrigerator space } \\
\text { - Unpredictable electricity } \\
\text { - Lack of time } \\
\text { - Difficult to discuss sexual issues } \\
\text { - Not yet implemented/available or recently introduced } \\
\text { - Not enough evidence for it/lack of information/not } \\
\text { effective, safe, or useful } \\
\text { - Refused } \\
\text { - Do not know } \\
\text { - Other, open-ended response }\end{array}$ \\
\hline Facilitator of provider recommendation & $\begin{array}{l}\text { What would make it easier or more likely for you to } \\
\text { recommend HPV vaccination to parents of girls in your } \\
\text { clinic (or school)? }\end{array}$ & $\begin{array}{l}\text { Select all that apply: } \\
\text { - Free or low-cost vaccine } \\
\text { - School-based program } \\
\text { - Parents/family who are supportive of HPV vaccine } \\
\text { - More data on vaccine safety } \\
\text { - More data on long-term efficacy } \\
\text { - No need for booster doses } \\
\text { - Fewer doses } \\
\text { - Nothing } \\
\text { - Vaccine publicly available } \\
\text { - More general information (nonspecific) } \\
\text { - Educational campaigns, promotions, and advertise- } \\
\text { - Grents (nonspecific) } \\
\text { - Meetings and campaigns targeting parents - Refused } \\
\text { - Do not know } \\
\text { - Other, open-ended response }\end{array}$ \\
\hline Comfort with recommending vaccine & $\begin{array}{l}\text { How comfortable do you feel recommending the HPV } \\
\text { vaccine to parents of girls in your clinic (or school)? }\end{array}$ & $\begin{array}{l}\text { Select only one: } \\
\text { - Very comfortable } \\
\text { - A little comfortable } \\
\text { - A little uncomfortable } \\
\text { - Very uncomfortable } \\
\text { - Refused } \\
\text { - Do not know }\end{array}$ \\
\hline Reason for discomfort & What makes you feel uncomfortable? & $\begin{array}{l}\text { Select all that apply: } \\
\text { - Uncomfortable discussing sexual health/sexually trans- } \\
\text { mitted infections } \\
\text { - Costs are too high } \\
\text { - Unproven efficacy/not enough long-term data } \\
\text { - Concerns about vaccine safety/side effects } \\
\text { - Too many doses } \\
\text { - Might need a booster dose } \\
\text { - Vaccine not publicly available } \\
\text { - Nothing } \\
\text { - General uncertainty/concerns about vaccine messaging } \\
\text { - Refused } \\
\text { - Do not know } \\
\text { - Other, open-ended response }\end{array}$ \\
\hline
\end{tabular}


HPV vaccine: positive aspects

HPV vaccine: negative aspects

What is your opinion about the benefits of HPV vaccination? Select all that apply:

- Vaccine is safe/few adverse events

- Long-lasting immunity

- Protects against cervical cancer

- Protects against genital warts

- Patients can receive other vaccinations at the same visit

- Vaccination could reduce the need for routine cervical cancer screening

- Vaccination gives providers opportunity to discuss sex-

ual health issues with patients

- I have never heard of the HPV vaccine

- Nothing/I do not like anything about the vaccine

- Prevents other HPV-related outcomes

- Refused

- Do not know

- Other, open-ended response

Select all that apply: vaccination?

- Unsafe/causes adverse events

- Vaccination does not lead to long-lasting immunity

- Vaccine does not protect against all HPV types/not all cervical cancer

- Cost

- Shot is painful

- Three doses/too many doses

- Vaccination would not reduce need for routine cervical cancer screening

- Requires providers to discuss sexual health issues with girls/parents

- Likelihood of girls having sex would increase if vaccinated

- I have never heard of the HPV vaccine

- Nothing/I like everything about the vaccine

- Negative perceptions

- Lack of parental support

- Not approved for all ages

- Implementation problems

- Not enough evidence

- Need better awareness/education campaigns

- Refused

- Do not know

HPV, human papillomavirus. 